\title{
Protocolos clínicos de actuación ante el proceso de donación y extracción de órganos y tejidos para trasplante en donación en muerte encefálica
}

\section{Clinical protocols during the process of organ and tissue donation in encephalic death}

JM. Dueñas Jurado

Coordinador Sectorial. Hospital Universitario Reina Sofía. Córdoba

Correspondencia: José Ma Dueñas Jurado E-mail: jmd_jurado@hotmail.com

\section{Resumen}

En el proceso de donación y trasplante de órganos habrá un protocolo de puntos clave para mejorar resultados. La detección de donantes tiene lugar principalmente en las unidades de medicina intensiva (UMI), urgencias y plantas neurológicas. La etiología más frecuente de muerte encefálica (ME) suele ser accidentes cerebrovasculares agudos (ACVA). El mantenimiento del donante es en las UMI. La ME desencadenará cambios fisiopatológicos: inestabilidad hemodinámica, pérdida de respiración espontánea, hipotermia y desequilibrio hormonal e hidroelectrolítico. El diagnóstico de ME se realizará por tres médicos que realizarán una completa exploración neurológica, y a veces se recurrirá a pruebas diagnósticas instrumentales según la legislación española. En los casos judiciales será imprescindible la colaboración del médico forense, que valorará el caso e informará al juzgado para su autorización. Es importante la información a la familia de la evolución clínica, el exitus y la posibilidad de donación para el consentimiento familiar a la donación. Finalmente se programará una correcta extracción e implante de los órganos.

Palabras clave: Proceso. Donación. Trasplante.

\section{Abstract}

The process of organ and tissue donation has to be standardized to maximize results. Donor detection takes place mainly in Intensive care units, emergency areas and neurology wards. The most common etiology of encephalic death is acute stroke. Donor management occurs in intensive care units. Encephalic death promotes physiopathological changes that need constant and intensive correction, such as hemodynamic unstability, loss of regular breathing, hypothermia and an array of changes in the hormone and electrolyte level. According to the Spanish legislation, the diagnosis of encephalic death must be signed by three doctors that will perform a neurological exploration, as well as the realization of diagnostic tests. When dealing with a legal case it is necessary the cooperation of a forensic doctor that will assess the case and inform the judge about the authorization. It is important to inform the family about the clinical status, exitus and the possibility of donorship, in order to obtain their consent. Finally, there will be a programmed organ and tissue extraction, coordinated with the implantation.

Key words: Process. Donation. Transplant.
Fecha de recepción:

13.MAY.2015

Fecha de aceptación:

19.MAY.2015 


\section{Introducción}

La donación y el trasplante de órganos y tejidos en España, como consecuencia de un problema constante y universal, como es la escasez de órganos y tejidos a trasplantar, ha presentado una transformación continua y favorable en los últimos años. Así, desde el principio de los años noventa hasta nuestras fechas, se ha pasado de un escenario de 14 donantes por millón de población (pmp) en 1989, situando a España en un puesto bajo en el ranking europeo de donaciones, a 36 donantes pmp, primer lugar del mundo con una diferencia significativa, y que se va ampliando año tras año ${ }^{1}$. Varios factores ha contribuido a que una terapéutica como es el trasplante pueda beneficiar cada vez a más personas; así, entre ellos tenemos creación de la Organización Nacional de Trasplantes (ONT) en 1989, la red de coordinadores hospitalarios, la mejora de dotación de infraestructura, la formación de áreas hospitalarias, la colaboración de los medios de comunicación, etc. pero sin duda uno de los puntos básicos en la mejora de la donación y el trasplante fue la elaboración de la Ley 30/1979 sobre extracción y trasplantes de órganos. Es la ley básica donde se tratan los aspectos fundamentales y donde se aclaran los principios generales por los que se rigen todas las actividades relacionadas con la donación y el trasplante. Esta ley ha sido revisada y actualizada recientemente, el 28 de diciembre de 2012, en el Real Decreto 1723/2012 por el que se regulan las actividades de obtención, utilización clínica y coordinación territorial de los órganos humanos destinados al trasplante, y el 5 de julio de 2014 en el Real Decreto 9/2014 para la donación, obtención, evaluación, procesamiento, preservación, almacenamiento y distribución de células y tejidos humanos. La legislación contempla diversas formas de donación: en vida, en asistolia... pero sin duda la más importante de todas, dado el número de órganos y tejidos obtenidos, es la donación en muerte encefálica (ME). La ME se define como la pérdida irreversible, por causa conocida, de todas las funciones encefálicas.

En España, la donación en ME sigue siendo próxima al $90 \%$ de todas las donaciones que se producen. Dada esta importancia, la donación en ME será uno de los pilares fundamentales a vigilar, trabajar y desarrollar en todos los programas de donación y trasplantes (Figura 1).

En este capítulo analizaremos de manera general cada uno de los puntos a tener en cuenta a la hora de elaborar y poner en marcha un protocolo clínico de donación y trasplante en ME (Figura 2).

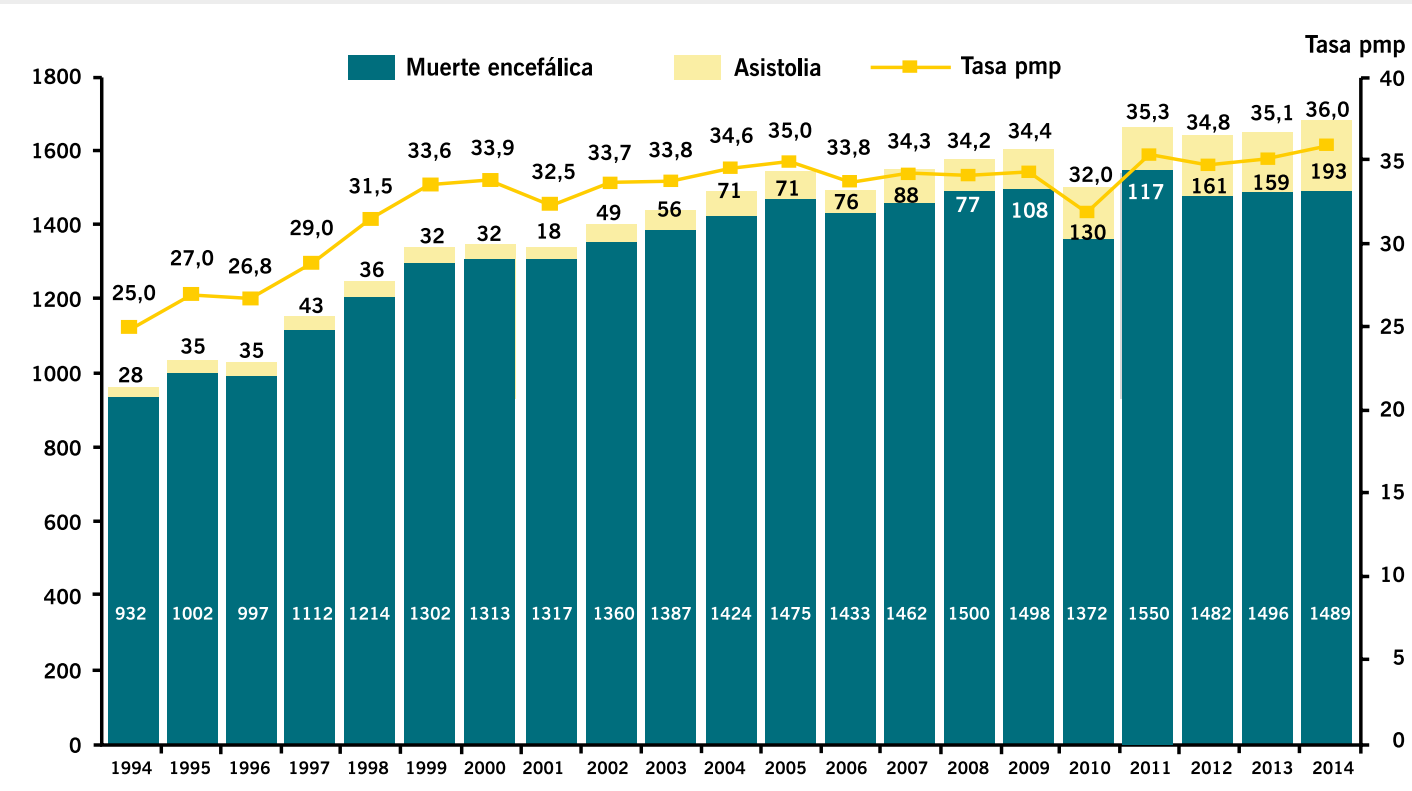

Figura 1.

Porcentaje de donantes en asistolia sobre el total de donantes. España, 1994-2014. 
Figura 2.

Esquema del proceso de donación y trasplante.

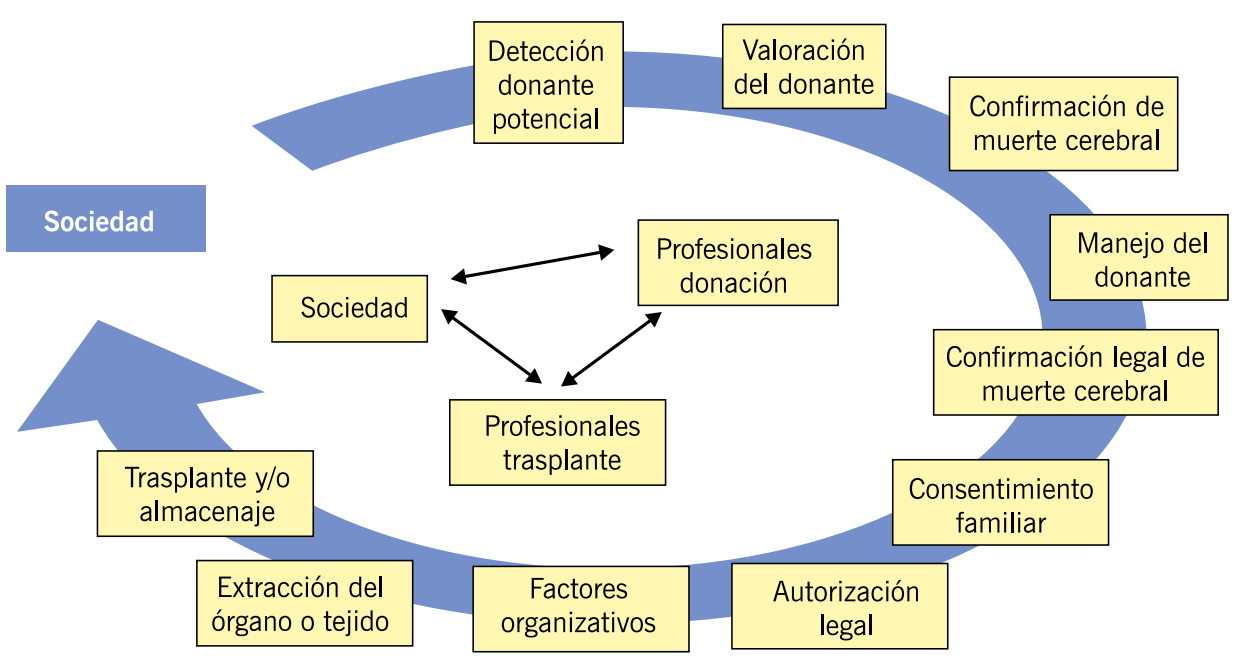

\section{Detección del donante en muerte encefálica}

La detección de donantes es el primer paso en el eslabón de la cadena donación-trasplante. Es uno de los puntos más importantes de todo el proceso, ya que los estudios epidemiológicos muestran que la incidencia de ME es similar en los países desarrollados, con lo cual la diferencia existente en el número de donantes entre hospitales, ciudades y países solo sería explicable por un problema de infradetección.

Aproximadamente un $2 \%$ de las personas fallecidas en un hospital lo hacen en situación de ME, y esta cifra se eleva a un $12-14 \%$ si nos circunscribimos al área de medicina intensiva. De ahí la importancia de la formación, sensibilización y colaboración de todos los profesionales de la sanidad para que la detección de potenciales donantes sea del $100 \%^{2,3}$.

El hecho de que el mayor número de potenciales donantes se encuentre en las unidades de medicina intensiva ha contribuido a que los especialistas de estas áreas (médicos intensivistas) se hayan incorporado mayoritariamente a la red de coordinadores de trasplantes en los últimos años ${ }^{4}$.

A la hora de la detección de potenciales donantes habrá que indicar que tanto la etiología como el perfil de los donantes en ME han ido cambiando a lo largo de los años. Así, en cuanto a la etiología, si bien a primeros de los años 90 la causa más frecuente de ME eran los traumatismos craneoencefálicos (TCE) por accidentes de tráfico, con cifras próximas al 50\% de todas la ME, en la actualidad la causa más frecuente de ME son los accidentes cerebrovasculares agudos (ACVA), tanto isquémicos como hemorrágicos, con cifras superiores al 65\% de todas las ME (Figura 3).

El perfil de donante en la actualidad es mayoritariamente masculino, de grupo sanguíneo A u 0 , y la edad ha evolucionado desde una edad media inferior a 35 años en los primeros años de los 90 hasta los 59,4 años de edad media que tenemos en la actualidad. En 2014, el 83\% de los donantes eran mayores de 45 años y el 53,9\% tenían más de 60 años. La utilización de estos órganos ha sido posible, entre otros factores, gracias al desarrollo de técnicas quirúrgicas, nuevos métodos de conservación, avance con terapias inmunosupresoras y evolución también del perfil del receptor de órganos (Figura 4).

\section{Mantenimiento del potencial donante de órganos y tejidos en muerte encefálica}

La ME desencadenará a corto plazo, si no actuamos con celeridad y buena praxis, la parada cardiaca y el cese irreversible de la actividad cardiaca y circulatoria, con la consiguiente pérdida de órganos. Por ello, es importante un buen mantenimiento del potencial donante de órganos en $\mathrm{ME}$, en condiciones de perfusión y oxigenación óptimas, que nos aseguren una correcta viabilidad de los órganos para ser trasplantados. En el caso de tejidos como el óseo, 


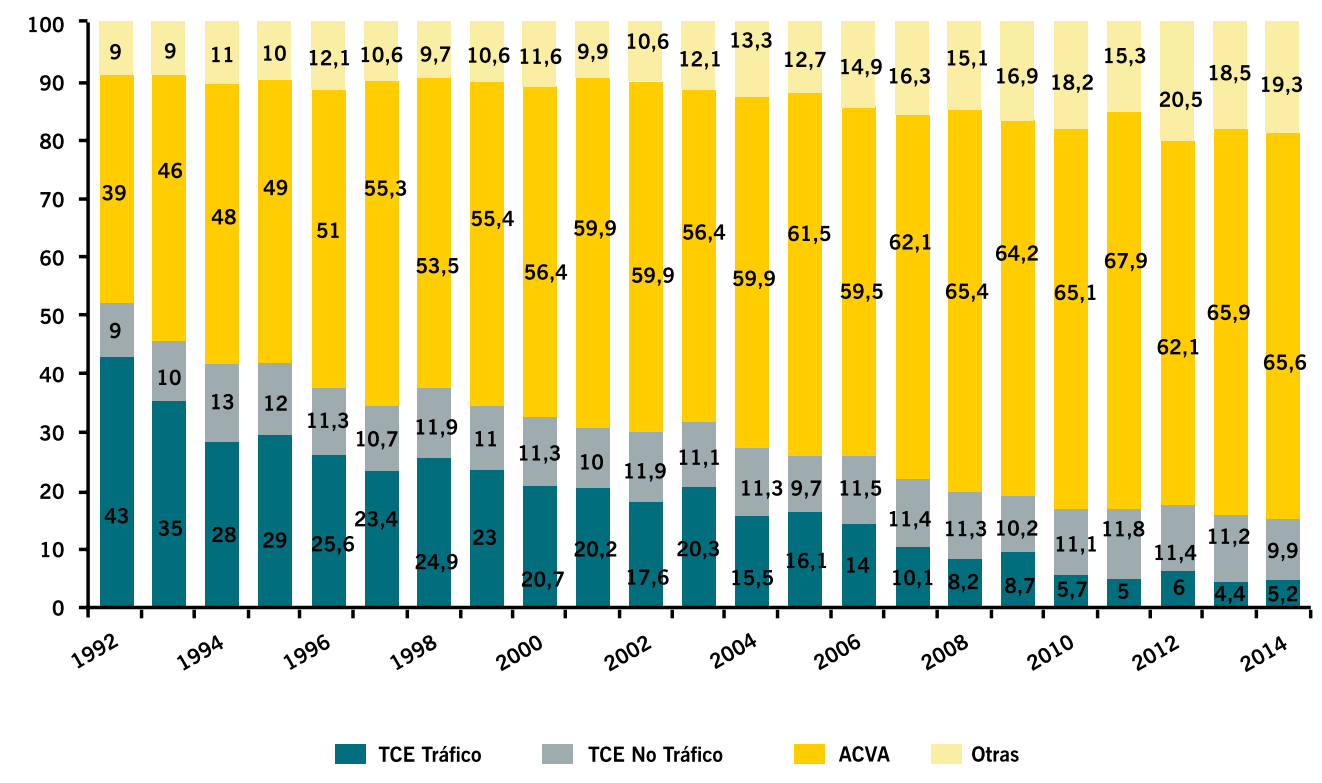

Figura 3.

Causa de muerte de los donantes en España, 1992-2014.

Figura 4.

Evolución de la edad de los donantes en España, 2000-2014.

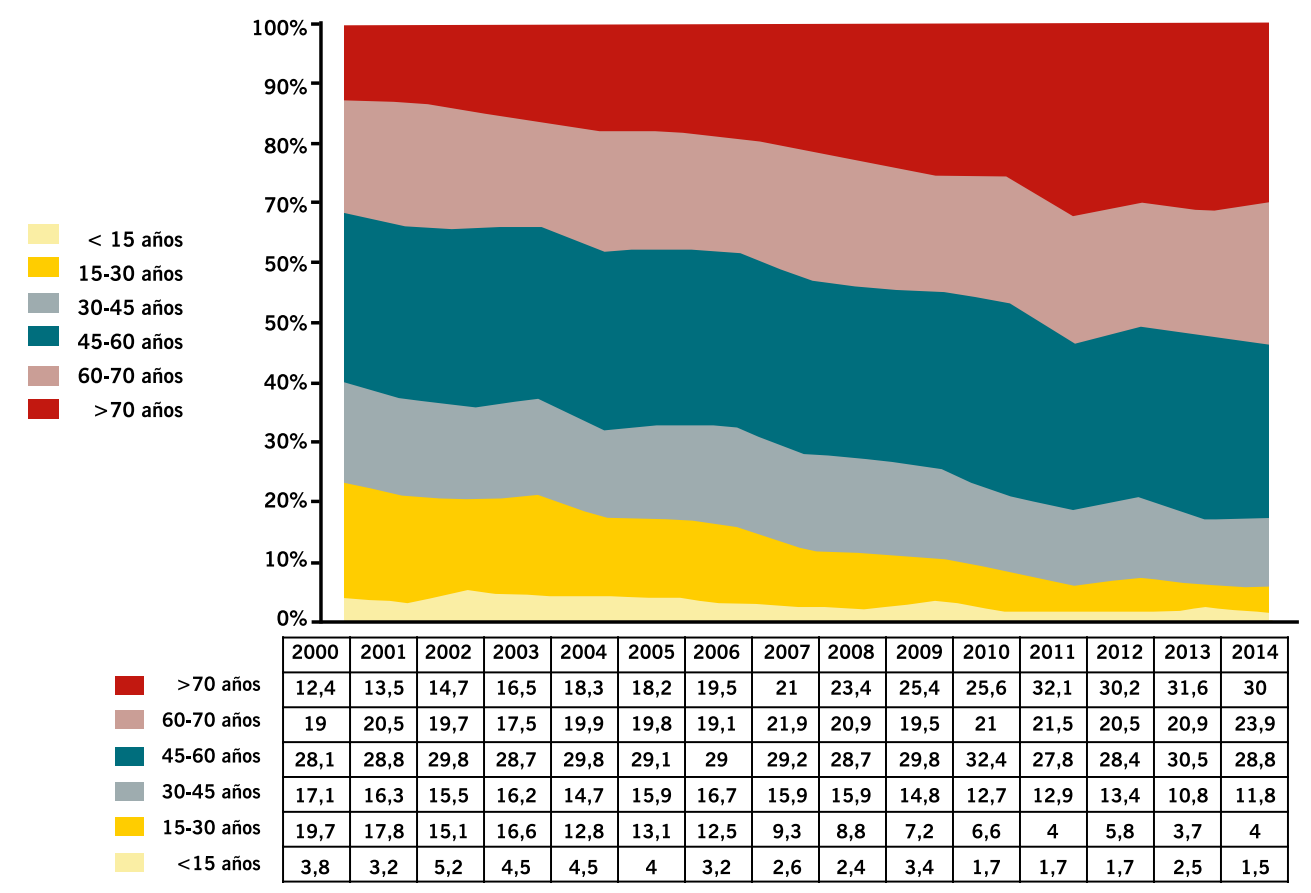


córneas, etc., el mantenimiento del donante no es tan importante, pues pueden extraerse incluso en el caso de situación de cese de la actividad circulatoria en estos tejidos.

La ME transforma al potencial donante en un "paciente crítico e inestable", y de ahí que su manejo se haga fundamentalmente por intensivistas en las unidades de medicina intensiva, bajo una monitorización estricta y específica, y una terapéutica enérgica y adecuada. La monitorización de estos pacientes debe incluir las constantes vitales continuas (electrocardiografía, presión arterial, presión venosa central, pulsioximetría, temperatura, diuresis), analítica general y pruebas complementarias específicas (cultivos microbiológicos, radiografías, ecografías...).

El tratamiento del potencial donante de órganos irá encaminado a contrarrestar las alteraciones fisiopatológicas que se producen en la ME, entre las que destacan:

- Pérdida de la respiración espontánea, lo cual se trata con ventilación mecánica, de tal manera que el respirador nos asegurará una buena oxigenación y ventilación del donante.

- Inestabilidad hemodinámica. Dependiendo de la fase de instauración de la ME podremos tener episodios de hipertensión, que se tratarán con fármacos antihipertensivos (betabloqueantes principalmente); hipotensión grave, tratada con fluidoterapia (administración de sueros y líquidos) y fármacos inotrópicos (noradrenalina

Figura 5. Lesión hemorragica en el sistema nervioso central que podría ser compatible con evolución a muerte encefálica.

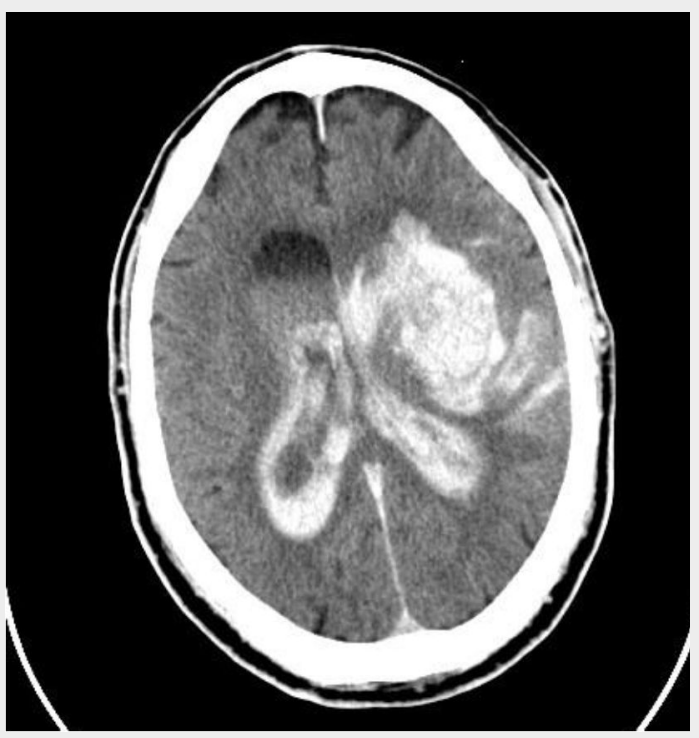

y dopamina fundamentalmente); y episodios de arritmias que se tratarán con la corrección del medio interno de organismo, y en el caso de taquicardias con antiarrítmicos (sulfato de magnesio, betabloqueantes), o en el caso de bradicardias con fármacos inotrópicos (adrenalina , dopamina) o marcapasos.

- Pérdida del control de la temperatura por afectación del centro termorregulador, que se tratará con calentamiento artificial.

- Alteraciones del control del equilibrio hidroelectrolítico y hormonal del potencial donante, para lo que administraremos exógenamente aquellos elementos que encontremos carentes en los análisis y la clínica del sujeto.

El buen manejo del potencial donante de órganos es importante porque hasta un $30 \%$ de los posibles donantes en ME pueden perderse por parada cardiaca antes de su traslado al quirófano, y hasta el $50 \%$ de los donantes potenciales se perderían si no se hiciera un correcto mantenimiento por profesionales bien formados en las unidades de medicina intensiva.

\section{Diagnóstico de muerte encefálica}

\section{Condiciones diagnósticas}

Coma de etiología conocida y de carácter irreversible. Debe haber evidencia clínica o por neuroimagen de lesión destructiva en el sistema nervioso central compatible con la situación de ME (Figura 5).

\section{Exploración clínica neurológica}

a) El diagnóstico de muerte encefálica exige siempre la realización de una exploración neurológica que debe ser sistemática, completa y extremadamente rigurosa.

b) Inmediatamente antes de iniciar la exploración clínica neurológica hay que comprobar si el paciente presenta ${ }^{5,6,8}$ :

- Estabilidad hemodinámica.

- Oxigenación y ventilación adecuadas.

- Temperatura corporal superior a $32^{\circ} \mathrm{C}$, y en niños de hasta 24 meses de edad superior a $35^{\circ} \mathrm{C}$. Lo ideal es superior a $35^{\circ} \mathrm{C}$ en todos los casos.

- Ausencia de alteraciones metabólicas y endocrinas causantes del coma.

- Ausencia de sustancias o fármacos depresores o bloqueantes del sistema nervioso central (SNC). 
c) Los hallazgos fundamentales en la exploración neurológica son los siguientes ${ }^{9,10}$ :

- Coma arreactivo, sin ningún tipo de respuesta motora o vegetativa al estímulo doloroso producido en el territorio de los nervios craneales.

- Ausencia de reflejos troncoencefálicos (fotomotor, corneal, nauseoso, tusígeno, oculocefálicos y oculovestibulares).

- Ausencia de respuesta al test de atropina. Tras la administración intravenosa de 0,04 $\mathrm{mg} / \mathrm{kg}$ de sulfato de atropina no debe existir un incremento superior al $10 \%$ de la frecuencia cardiaca inicial antes de aplicar el fármaco.

- Apnea, demostrada mediante el "test de apnea" o de retirada de la ventilación mecánica, comprobando que no existen movimientos respiratorios torácicos ni abdominales cuando la $\mathrm{PCO}_{2}$ en sangre arterial se eleva a cifras mayores de $60 \mathrm{mmHg}$.

d) La presencia de actividad motora de origen espinal, espontánea o inducida, no invalida el diagnóstico de ME.

e) Condiciones que dificultan el diagnóstico clínico de ME. Algunas situaciones clínicas pueden dificultarlo o complicarlo al impedir que la exploración neurológica sea realizada de una forma completa o con la necesaria seguridad. Tales condiciones son:

- Pacientes con graves destrozos del macizo craneofacial o cualquier otra circunstancia que impida la exploración de los reflejos troncoencefálicos.

- Intolerancia al test de apnea.

- Hipotermia (temperatura corporal inferior o igual a $32{ }^{\circ} \mathrm{C}$ ).

- Intoxicación o tratamiento previo con sustancias o fármacos depresores del SNC.

\section{Periodo de observación}

El periodo de observación debe valorarse individualmente, teniendo en cuenta el tipo y la gravedad de la lesión causante, así como las pruebas instrumentales realizadas.

Siempre que el diagnóstico sea exclusivamente clíni$\mathrm{co}$, se recomienda repetir la exploración neurológica según los siguientes periodos:

a) A las seis horas en los casos de lesión destructiva conocida.

b) A las veinticuatro horas en los casos de encefalopatía anóxica. c) Si se sospecha o existe uso de fármacos o sustancias depresoras del SNC, el periodo de observación debe prolongarse, a criterio médico, según la vida media de los fármacos o sustancias presentes, y las condiciones clínicas y biológicas generales del paciente.

Los periodos de observación reseñados pueden acortarse o incluso omitirse a criterio médico, de acuerdo con las pruebas instrumentales de soporte diagnóstico realizadas (véase a continuación).

\section{Pruebas instrumentales de soporte diagnóstico}

a) No son obligatorias, excluyendo las siguientes situaciones ${ }^{5,6,8}$ :

- Las condiciones que dificultan el diagnóstico clínico, a las que antes nos hemos referido.

- Ausencia de lesión destructiva cerebral demostrable por evidencia clínica o por neuroimagen.

- Cuando la lesión causal sea primariamente infratentorial, en cuyo caso la prueba instrumental a realizar debe demostrar la existencia de lesión irreversible de los hemisferios cerebrales (electroencefalograma o prueba de flujo sanguíneo cerebral).

Sin embargo, con el fin de complementar el diagnóstico y acortar el periodo de observación, sería recomendable la realización de alguna prueba instrumental.

b) El número y el tipo de tests diagnósticos instrumentales a utilizar debe valorarse de forma individual, atendiendo a las características particulares de cada caso y a las aportaciones diagnósticas de las técnicas empleadas. Las pruebas instrumentales diagnósticas son de dos tipos:

- Pruebas que evalúan la función neuronal:

- Electroencefalografía.

- Potenciales evocados.

- Pruebas que evalúan el flujo sanguíneo cerebral:

- Arteriografía cerebral de los cuatro vasos.

- Angiografía cerebral por sustracción digital (arterial o venosa), mediante tomografía computarizada multicorte, con o sin estudio de perfusión cerebral, mediante resonancia magnética.

- Angiogammagrafía cerebral con radiofármacos capaces de atravesar la barrera hematoencefálica intacta.

- Sonografía Doppler transcraneal.

Para el diagnóstico de ME, y si así lo permiten los avances científicos y técnicos en la materia, se podrá 
utilizar cualquier otra prueba instrumental no incluida en la relación previa siempre que acredite absoluta garantía diagnóstica.

\section{Diagnóstico de muerte encefálica no complicado}

Ante un coma de causa conocida, y una vez excluida la existencia de situaciones que pudieran dificultar el diagnóstico clínico, un paciente que presente una exploración clínica de ME y una prueba instrumental de soporte diagnóstico concluyente puede ser diagnosticado de ME sin ser preciso esperar el periodo de observación.

\section{Diagnóstico de muerte encefálica en situaciones especiales}

En aquellas condiciones clínicas en las que existen circunstancias que dificultan o complican el diagnóstico clínico, cuando no haya lesión destructiva cerebral demostrable por evidencia clínica o por neuroimagen, y cuando exista una lesión causal que sea primariamente infratentorial, además de la exploración neurológica deberá realizarse, al menos, una prueba instrumental de soporte diagnóstico confirmatoria.

\section{Recién nacidos, lactantes y niños}

- El diagnóstico clínico en estos casos se basa en los mismos criterios que en los adultos, aunque con algunas peculiaridades. La exploración neurológica en neonatos y lactantes pequeños debe incluir los reflejos de succión y búsqueda. En neonatos, especialmente los pretérmino, la exploración clínica debe repetirse varias veces, ya que algunos reflejos del tronco pueden no haberse desarrollado o ser de incipiente aparición, lo que hace a estos reflejos muy vulnerables. A su vez, en los niños de hasta 24 meses de edad, la exploración clínica para el diagnóstico de ME se realizará previa comprobación de que se cumple la exigencia de temperatura corporal especificada.

- Cuando se utilicen pruebas instrumentales de soporte diagnóstico en los niños se tendrán en cuenta las peculiaridades técnicas de los mismos. Por tanto, las pruebas deberán ajustarse a la edad, a las condiciones clínicas y a los estándares y las recomendaciones internacionales de las diferentes sociedades científicas.
- El periodo de observación recomendado varía con la edad y con las pruebas instrumentales realizadas:

- Neonatos pretérmino: aunque no existen guías internacionalmente aceptadas, se recomienda un periodo de observación de 48 horas. Este periodo de observación se podrá acortar a criterio médico, de acuerdo con las pruebas instrumentales de soporte diagnóstico realizadas, y podrá omitirse si se realiza una prueba diagnóstica que muestre, de forma inequívoca, ausencia de flujo sanguíneo cerebral.

- Neonatos (desde la 37 semana de gestación hasta los 30 días de edad): 24 horas. Este periodo de observación podrá acortarse a criterio médico, de acuerdo con las pruebas instrumentales de soporte diagnóstico realizadas y podrá omitirse si se realiza una prueba diagnóstica que muestre, de forma inequívoca, ausencia de flujo sanguíneo cerebral.

- Niños de más de 30 días y hasta 24 meses de edad: 12 horas. Este periodo de observación podrá acortarse a criterio médico, de acuerdo con las pruebas instrumentales de soporte diagnóstico realizadas, y podrá omitirse si se realiza una prueba diagnóstica que muestre, de forma inequívoca, ausencia de flujo sanguíneo cerebral.

\section{Autorización judicial}

Tras el diagnóstico de ME, si el fallecimiento fuera por un proceso judicial, como puede ser TCE, signos de violencia, autolisis u otra etiología no certificable por causa médica, sería imprescindible contactar con Juzgado de Guardia, e informar del fallecimiento de la persona, y la necesidad de autorización judicial para la donación-extracción de órganos, con la mayor premura para continuar con la "carrera contrarreloj" que supone el proceso de donación y trasplante. Generalmente, con la exploración clínica del donante a pie de cama y con la transmisión de información clínica al forense, el juez tiene suficiente información para autorizar la donación y el trasplante de órganos. Posteriormente al trasplante siempre se notificará por escrito a su señoría el resultado de la donación y el trasplante de esos órganos.

\section{Permiso de donación familiar}

Tan pronto como tengamos el diagnóstico de ME y la autorización judicial en el caso esta última de que 
sea precisa, pasaremos a la entrevista familiar, en la que se informará del fallecimiento por el médico que trataba al paciente. Tras esta información, la viabilidad de la donación, si no existen contraindicaciones médicas, dependerá de la entrevista que realizaremos a la familia. En el caso de la solicitud de la donación, lo fundamental es una relación de ayuda con la familia que está sufriendo el dolor de la pérdida ${ }^{11}$.

Varios factores influyen en esta entrevista, como es el trato recibido por la familia durante todo el proceso, preconceptos socioculturales, la manera de aceptación de la relación de ayuda, ansiedad, falta de experiencia del profesional que hace entrevista..

España es uno de los países que destacan por su solidaridad a la hora de la aceptación de la donación, y en los últimos años las negativas familiares a la donación se han reducido notablemente (Figura 6).

La labor del coordinador no acaba aquí con la familia, sino que deberá atender y ayudar a los familiares en todas sus necesidades, hasta la entrega del cadáver con un inapreciable aspecto externo de la extracción de órganos.

\section{Factores logísticos y de organización de la donación-trasplante}

Tras el diagnóstico de ME y las necesarias autorizaciones, serán obligatorias la selección y la evaluación de los órganos y tejidos del donante, para confirmar aquellos que son aptos para el trasplante, así como simultáneamente la preparación de toda la logística intrahospitalaria y extrahospitalaria para proceder a la extracción de órganos, contactando con la oficina de la ONT con el fin de realizar una asignación correcta de los distintos órganos a trasplantar a un receptor, de acuerdo con los criterios previamente establecidos y acordados entre equipos y administraciones autonómicas.

Desde la ONT se ofertan los órganos a equipos trasplantadores, que en alguna ocasión están a bastante distancia del hospital donde se produce la donación, con lo cual el proceso aumenta en tiempo y en número de personas que intervienen. No solamente colaboran personal sanitario y judicial, sino que a veces se requiere la implicación profesional de aeropuertos, autoridades... El coordinador de trasplantes será el encargado de dirigir, velar y facilitar la tarea de todos los implicados en esta cadena, así como de adoptar las decisiones necesarias para que todo funcione a la perfección.

\section{Extracción y trasplante}

El proceso de donación y trasplante comienza en la sociedad con un donante que, tras la ME, facilita la donación y el trasplante de sus órganos o tejidos sanos a otro miembro de la sociedad, que es el receptor, con unos órganos o tejidos dañados por una enfermedad que no se puede solucionar con otro tratamiento convencional que no sea el trasplante.

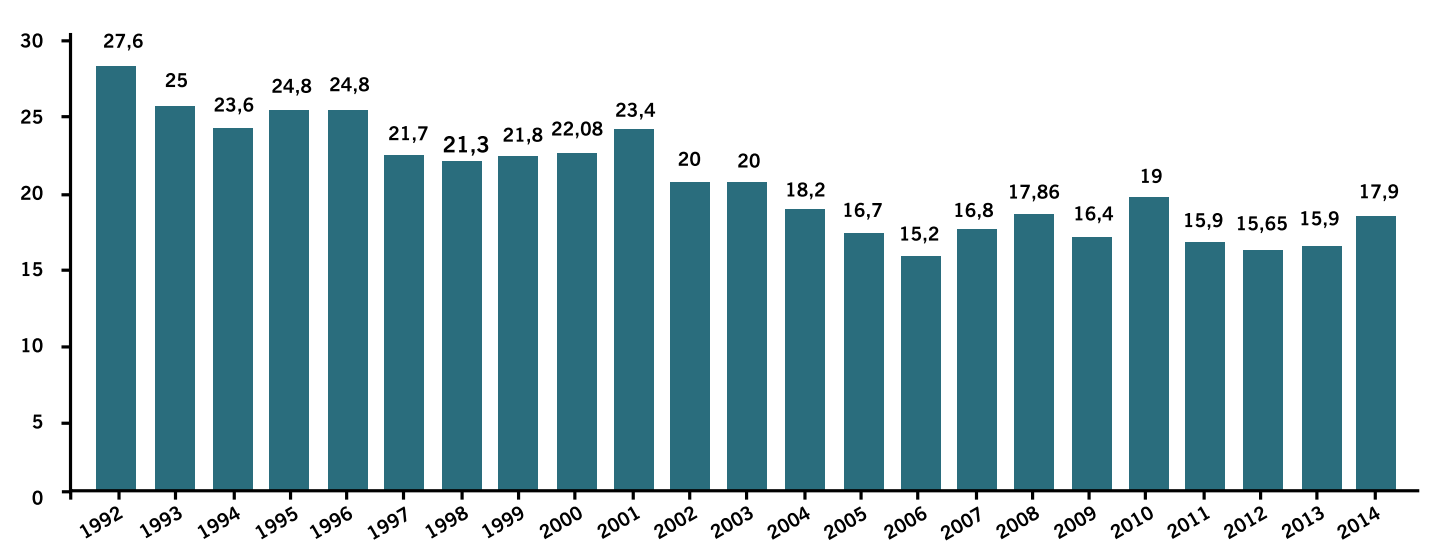

Figura 6.

Porcentaje de negativas familiares a la donación, España 1992-2014. 
La figura del coordinador de trasplantes sigue siendo pieza clave en el quirófano para organizar la extracción y el implante del órgano extraído.

Hoy en día, los progresos en técnicas quirúrgicas, legislación favorable, preservación de órganos, nuevas pautas de inmunosupresión y cuidados postoperatorios realizados en las unidades de cuidados intensivos han posibilitado que el trasplante de órganos deje de ser un procedimiento experimental para ser una alternativa terapéutica en enfermos terminales.
Los avances científicos, el desarrollo de bancos de tejidos, así como una legislación clara y específica para la donación y el trasplante, han conseguido que los trasplantes de células y tejidos sean una práctica habitual en las terapias de hoy en día.

Los autores declaran no tener ningún conflicto de intereses.

\section{Bibliografía}

1. Datos Donación y trasplante. Memoria ONT 2013. Disponible en: http://www.ont.es/infesp/Paginas/ Memorias.aspx

2. Heran MK, Heran NS, Shemie SD. A review of ancillary test in evaluating brain death. Can J Neurol Sci. 2008;35:409-19.

3. Morenski JD, Oro JJ, Tobias JD, Sing A. Determination of death by neurological criteria. J Intensive Care Med. 2003;18(4):211-21.

4. Matesanz R, et al. Guía de buenas prácticas en el proceso de donación de órganos. Madrid: Organización Nacional de Trasplantes; 2011.

5. Ley 30/1979, de 27 octubre, sobre extracción y trasplante de órganos. BOE no 266 de 6 de noviembre de 1979 .

6. Real Decreto $1723 / 2012$, de 28 de diciembre, por el que se regulan las labores de obtención, utilización clínica y coordinación territorial de los órganos humanos destinados al trasplante, y se establecen requisitos de calidad y seguridad. BOE n 313 de 29 de diciembre de 2012.

7. Real Decreto Ley 9/2014 por el que se establecen las normas de calidad y seguridad para la donación, la obtención, evaluación, procesamiento, preservación, almacenamiento y la distribución de las células y tejidos humanos. BOE n 163 de julio de 2014.

8. Directiva 2010/45/EU, sobre normas de calidad y seguridad de los órganos humanos destinados al trasplante. Diario Oficial de la Unión Europea, 7 de julio de 2010.

9. Heran MK, Heran NS, Shemie SD. A review of ancillary test in evaluating brain death. Can J Neurol Sci. 2008;35:409-19.

10. Morenski JD, Oro JJ, Tobias JD, Sing A. Determination of death by neurological criteria. J Intensive Care Med. 2003;18(4):211-21.

11. Matesanz R. El modelo español de coordinación y trasplantes. $2^{\circ}$ ed. Madrid: Aula Médica; 2008. 